Faculty of Science

Faculty Publications

Marine growth patterns of southern British Columbia chum salmon explained by interactions between density-dependent competition and changing climate Allan J. Debertin, James R. Irvine, Carrie A. Holt, Gladys Oka, and Marc Trudel July 2017

(C) 2017 Her Majesty the Queen in right of Canada. This is an open access article distributed under the terms of the Creative Commons Attribution 4.0 International License. http://creativecommons.org/licenses/by/4.0

This article was originally published at:

https://doi.org/10.1139/cjfas-2016-0265

Citation for this paper:

Debertin, A.J.; Irvine, J.R.; Holt, C.A.; Oka, G.; \& Truedel, M. (2017). Marine growth patterns of southern British Columbia chum salmon explained by interactions between density-dependent competition and changing climate. Canadian Journal of Fisheries and Aquatic Sciences, 74(7), 1077-1087. https://doi.org/10.1139/cjfas2016-0265 


\title{
Marine growth patterns of southern British Columbia chum salmon explained by interactions between density-dependent competition and changing climate
}

\author{
Allan J. Debertin, James R. Irvine, Carrie A. Holt, Gladys Oka, and Marc Trudel
}

\begin{abstract}
Thirty-nine years of scale growth measurements from Big Qualicum River chum salmon (Oncorhynchus keta) in southern British Columbia demonstrated that competition and climate variation affect marine growth and age-at-maturity. A longitudinal study design that accounted for correlation among individuals revealed growth at all ages was reduced when the biomass of North American chum, sockeye (Oncorhynchus nerka), and pink salmon (Oncorhynchus gorbuscha) was high. When North Pacific Gyre Oscillation (NPGO) was positive, indicating increased primary productivity, predicted growth increased. Climate variation influenced competition effects. For instance, density-dependent competition effects increased when NPGO became more positive and Pacific Decadal Oscillation became more negative (indicating cool conditions), causing the greatest range in predicted scale size. Chum salmon are likely to exhibit continued reduction in growth at age due to increased ocean temperatures driven by climate change and high aggregate salmon biomass that includes hatchery releases. If evidence of biomass and climate effects presented here are common among Pacific salmon populations, reduction of hatchery releases should be considered.
\end{abstract}

Résumé : Des mesures sur 39 ans de la croissance des écailles de saumons kétas (Oncorhynchus keta) de la Grande rivière Qualicum, dans le sud de la Colombie-Britannique, démontrent que la concurrence et les variations climatiques ont une incidence sur la croissance en mer et l'âge à la maturité. Un plan d'étude longitudinale qui tient compte de la corrélation entre individus révèle que la croissance à tous les âges est plus faible quand la biomasse des saumons kétas, sockeyes (Oncorhynchus nerka) et roses (Oncorhynchus gorbuscha) d'Amérique du Nord est élevée. Quand l'oscillation du tourbillon nord-pacifique (OTPN) est positive, indiquant une productivité primaire accrue, la croissance prédite augmente. Les variations du climat ont également une incidence sur ces effets de concurrence. Les effets de la concurrence dépendant de la densité augmentent quand l'OTPN devient plus positive et l'oscillation décennale du Pacifique, plus négative (indiquant des conditions fraîches), ce qui produit la plus grande fourchette de tailles d'écailles prédites. Il est probable que les saumons kétas continueront de présenter une diminution de la croissance selon l'âge en raison de la hausse des températures océaniques causée par les changements climatiques et de la forte biomasse totale de saumons incluant les individus issus d'écloseries. Si les indices d'effets de la biomasse et du climat relevés dans la présente étude s'avéraient répandus dans les populations de saumons du Pacifique, il serait pertinent d'examiner la possibilité de réduire les lâchers de poissons issus d'écloseries. [Traduit par la Rédaction]

\section{Introduction}

There have been recent downward trends in size-at-age for many Pacific salmon (Oncorhynchus spp.) populations (Pyper and Peterman 1999; Agler et al. 2013; Jeffrey et al. 2017), which are often accompanied with increased age-at-maturity (Bigler et al. 1996; Morita et al. 2005; Morita and Fukuwaka 2007). Relatively high abundances of salmon, especially during periods of low marine productivity, have been hypothesized to cause reductions in size-at-age and salmon survival (e.g., Irvine and Akenhead 2013; Yasumiishi et al. 2016). Density-dependent competition for common prey resources is presumably greatest for the three most abundant species, chum (Oncorhynchus keta), pink (Oncorhynchus gorbuscha), and sockeye salmon (Oncorhynchus nerka), each of which is primarily planktivorous (Davis et al. 2004; Kaeriyama et al. 2004; Ruggerone et al. 2012). Climate variation affects salmon growth (Helle and Hoffman 1998; Jeffrey et al. 2017), as the bioenergetics of salmonids can be altered by changes in the amount and composition of salmon prey (Beauchamp 2009) in conjunction with changes in ocean temperature and productivity (Hare and Mantua 2000; Farley et al. 2011; Siddon et al. 2013). Nevertheless, the relative importance of competition and climate variation and interactions between them remains uncertain for many Pacific salmon populations. Here, we test whether growth patterns for Big Qualicum chum salmon in southern British Columbia (BC) can be explained by competition and climate variation.

Received 23 June 2016. Accepted 15 November 2016.

A.J. Debertin.* Fisheries and Oceans Canada, Pacific Biological Station, 3190 Hammond Bay Road, Nanaimo, BC V9T 6N7, Canada; Department of Integrative Biology, Science Complex, University of Guelph, Guelph, ON N1G 2W1, Canada.

J.R. Irvine and C.A. Holt. Fisheries and Oceans Canada, Pacific Biological Station, 3190 Hammond Bay Road, Nanaimo, BC V9T 6N7, Canada.

G. Oka. Fisheries and Oceans Canada, Pacific Biological Station, 3190 Hammond Bay Road, Nanaimo, BC V9T 6N7, Canada; Earth, Ocean, and

Atmospheric Sciences Department, 2020-2207 Main Mall, The University of British Columbia, Vancouver, BC V6T 1Z4, Canada.

M. Trudel. † Fisheries and Oceans Canada, Pacific Biological Station, 3190 Hammond Bay Road, Nanaimo, BC V9T 6N7, Canada; Department of Biology,

University of Victoria, P.O. Box 1700 Station CSC, Victoria, BC V8W 2Y2, Canada.

Corresponding author: Allan Jürgen Debertin (email: adeberti@uoguelph.ca).

*Present address: Department of Integrative Biology, Science Complex, University of Guelph, Guelph, ON N1G 2W1, Canada.

†Present address: Fisheries and Oceans Canada, St. Andrews Biological Station, 531 Brandy Cove Road, St. Andrews, NB E5B 2L9, Canada.

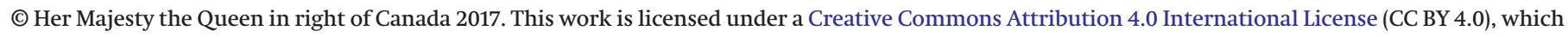
permits unrestricted use, distribution, and reproduction in any medium, provided the original author(s) and source are credited. 
Fig. 1. Schematic of the approximate marine distribution of southern British Columbia chum salmon (blue shading), Asian chum salmon (yellow shading), pink salmon (red lines), and sockeye salmon (black lines). Solid and dashed lines represent North American and Asian origin populations, respectively. Study population originates from the Big Qualicum River (BO) on eastern Vancouver Island, Canada. Maps are based on recovery location of known origin pink and chum salmon reported in Myers et al. (1996, 2007).

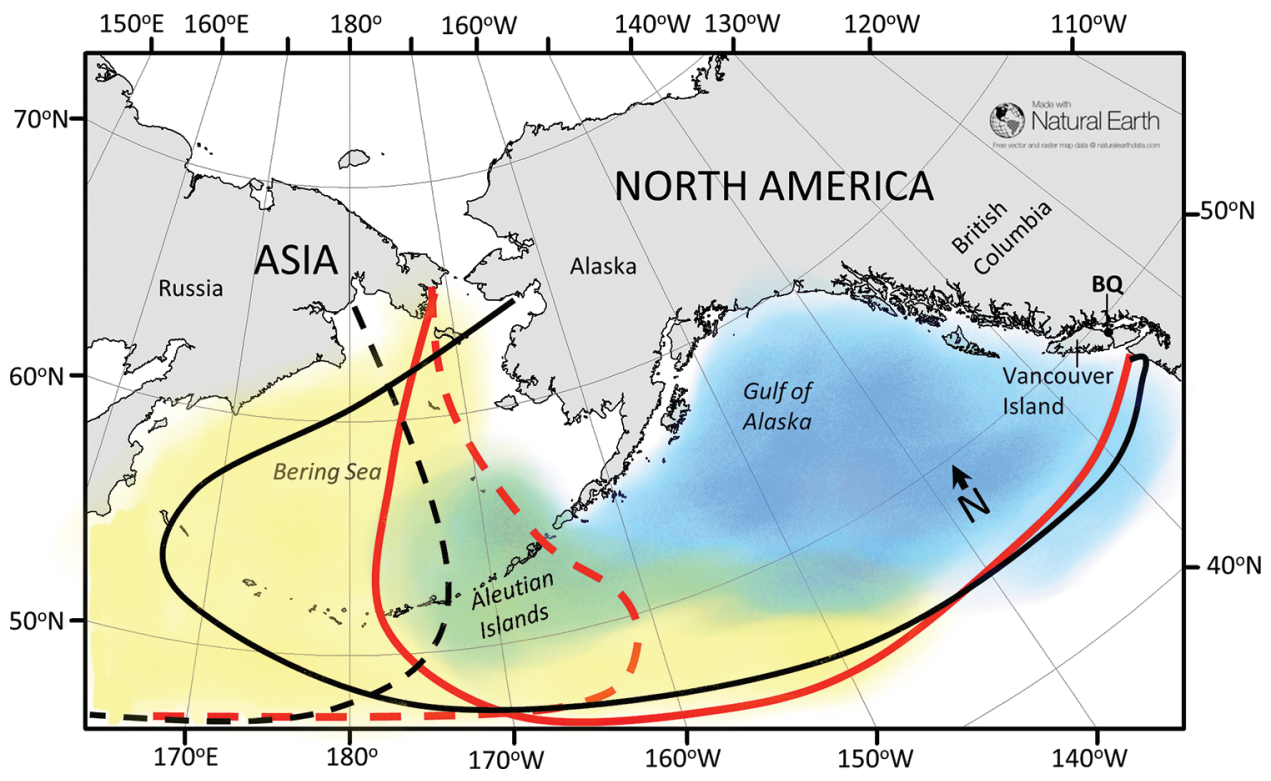

After entering the ocean as fry, young chum salmon from southern BC migrate northwards and then eastwards over the continental shelf following the counter-clockwise Alaska Current, moving offshore into deeper waters in late fall or early winter (Hartt and Dell 1986; Myers et al. 2007; Yasumiishi et al. 2016). It is thought that these salmon spend their second to penultimate years within the Gulf of Alaska, although some may migrate into the Bering Sea (Seeb et al. 2004). Rising temperatures in their final spring appear to trigger a return migration to coastal areas (Myers et al. 2007), with most fish arriving at their streams of origin during October to December. Southern BC chum salmon may compete for prey species with other populations of North American chum salmon, as well as North American sockeye and pink salmon, and possibly some Asian chum salmon (Tadokoro et al. 1996; Davis et al. 2004; Kaeriyama et al. 2004), as their marine distributions overlap (Azumaya and Ishida 2000; Myers et al. 2007; Urawa et al. 2009) (Fig. 1). In contrast, interactions with Asian pink and sockeye salmon are likely minimal due to limited spatial overlap (Myers et al. 1996, 2007). Chum salmon also opportunistically shift from nutritious lipid-rich crustaceans to less nutritious gelatinous zooplankton in years when other salmon species are abundant (Welch and Parsons 1993; Tadokoro et al. 1996), potentially causing reduced growth due to decreased energy intake, despite reduced competition of common prey species.

Trends in Pacific salmon growth, body size, survival, and abundance have also been hypothesized to be caused by large-scale changes in ocean temperatures, currents, and primary productivity (Helle and Hoffman 1998; Wells et al. 2006; Jeffrey et al. 2017). Weakening of subpolar and subtropical gyres decreases primary productivity (Schwing et al. 2002; Behrenfeld et al. 2006; Di Lorenzo et al. 2008) and has been associated with decreased salmon abundance (Kilduff et al. 2015), growth (Wells et al. 2006), and body size (Jeffrey et al. 2017) due to changes in prey species (Kaeriyama et al. 2004). As a result of lower metabolic costs (Farley et al. 2011; Siddon et al. 2013), cooler temperatures have been shown to increase the growth potential of Pacific salmonids. Large-scale changes in ocean circulation and temperature are represented by climate indices such as Pacific Decadal Oscillation (PDO; related to sea surface temperature anomalies, linked to changes in salmon production; Mantua et al. 1997), North Pacific Gyre Oscillation
(NPGO; reflects changes in the intensity of circulation in the North Pacific gyre, a strong indicator of changes in the planktonic ecosystem; Di Lorenzo et al. 2008), Northern Oscillation Index (NOI; based on sea surface height anomalies, dominated by El Niño and La Niña events; Schwing et al. 2002), and Multivariate El Niño southern oscillation (MEI; based on six oceanic and atmospheric variables, tracks El Niño and La Niña events; Wolter and Timlin 2011). Therefore, changes in climate indices may also explain the variation in growth patterns of Big Qualicum chum salmon.

To further our understanding of the synergistic effects of competition and climate variation on Pacific salmon scale growth, we tested the following hypotheses: (H1) growth is affected by density-dependent interactions with competing chum, sockeye, and pink salmon, such that the effect of competition is less for early growth and increases as fish age and the geographic distribution of potentially competing populations of salmon overlaps; (H2) growth is affected by climatic variation, such that growth of all ages is influenced similarly by changes in prey composition and the physical environment operating at large spatial scales; and (H3) the intensity of density-dependent competition on salmon growth is related to climate conditions and fish age, such that under particular environmental conditions, the intensity of densitydependent competitive effects varies with climate and age.

Pacific salmon that remain at sea are generally larger and more fecund than conspecifics that return after fewer years at sea (Beacham 1982; Beacham and Murray 1987; Dickerson et al. 2002). However, by remaining at sea, salmon also increase their risk of mortality before reproducing. Thus, similar to other semelparous species (Sebens 1987), chum salmon populations exhibit a phenotypic plastic response by maturing at an age that potentially maximizes fitness (Roff 1992; Kozłowski 1992; Morita and Fukuwaka 2007). This led to our fourth hypothesis (H4); chum salmon that have slower early marine growth will mature at an older age.

To the best of our knowledge, of the studies that have linked marine climate variability and salmon abundance to changes in sizeat-age (Martinson et al. 2008; Ruggerone et al. 2012; Agler et al. 2013; McPhee et al. 2016; Yasumiishi et al. 2016) and survival (e.g., Levin et al. 2001), none have used repeated measures of growth accounting for correlation among individuals within a single model (but see Marco-Rius et al. 2013 on freshwater growth patterns of sea trout, 
Salmo trutta). Most previous studies correlated scale size at a particular age with changes to the environment (e.g., sea surface temperature) and salmon abundance using separate models for each size at age (e.g., Ruggerone et al. 2012; Agler et al. 2013). Martinson et al. (2008) used multivariate adaptive regression splines to determine the effect of intraspecific competition on each age by using truncated splines to run separate regressions. Yasumiishi et al. (2016) used transfer function-noise models to test whether competition and environmental factors affect scale growth. McPhee et al. (2016) investigated correlations among growth zones in a mixed-effects model with individuals as random variables; however, that formulation of the mixed-effects model was not extended to evaluate impacts of different environmental covariates and density dependence. We used a statistically powerful longitudinal study design that estimated the effects of salmon biomass and climate variables separately from individual variation, tracking across growth stages within a single model (Hedeker and Gibbons 2006). Longitudinal study designs are commonly used for medical and psychological studies because of the ability to tease apart intra-individual variability from interindividual variability. By examining scale size data in this context, we were able to evaluate the effects of competition, oceanographic drivers, and the cumulative impact of those factors on growth while accounting for individual heterogeneity.

\section{Methods}

\section{Data collection}

\section{Study population}

We sampled a population of chum salmon that spawns in the Big Qualicum River that drains into the Strait of Georgia between Vancouver Island and mainland BC (Fig. 1). Big Qualicum chum salmon fry migrate to the ocean in March through June (Fraser et al. 1983) and return as adults to spawn after spending 3 to 5 (usually 4) years at sea (Fraser et al. 1983; Oka et al. 2012). Adult chum salmon returning to the lower Big Qualicum River were sampled for sex, length, and scales at a counting fence from 1971 to 2010. Scales were placed on cards, and acetate impressions were made of each card for subsequent analysis. Our goal for each year was to examine scales from randomly selected individuals (25 males and 25 females) captured at the counting fence for each age-atmaturity (i.e., individuals that spent 3 , 4 , or 5 years at sea). Scales were taken above the lateral line near where it intersects with a line from the back of the dorsal fin to the front of the anal fin.

\section{Scale analysis}

Using methods and results from Oka et al. (2012), scales were examined using an Olympus $\mathrm{BH} 2$ compound microscope at 250x magnification, and measurements of scale growth were completed using Media Cybernetic's Image Pro Plus version 6.2 image analysis software. We focused on five annual growth zones, growth until the first sea winter (SW1) to growth to the last sea winter (SW3, SW4, or SW5). The yearly incremental radial growth of each scale was measured along the longest anterior axis starting from the middle of the scale for SW1, then for all other growth zones, the outer edge of the previous sea winter to the edge of the annulus of the year of interest, until reaching the outer margin of the scale for the final year. Scale readings were considered to be reasonable accurate and repeatable using quality assurance protocol (for further details see Oka et al. 2012).

Although a relationship between salmon scale radius size and fish length has been well established in the literature (e.g., Marr 1943; Ricker 1973, 1976), in common with many other studies (e.g., McCarthy et al. 2008; Hogan and Friedland 2010; Marco-Rius et al. 2013), scale sizes were not converted to body length or mass estimates, as it would introduce additional errors as a result of $(i)$ scale reabsorption of the final annuli during the final year reducing accuracy (Seo et al.
2006) and (ii) uncertainty in the relationship between scale growth to body growth. Scale radius was correlated with fork length (Pearson $r=$ $0.47, p<0.001$; fish length data available from 1998 to 2010). Some scale reabsorption affecting the accuracy of the final scale radii measurements was likely, but this would not affect the accuracy of scale measurements for younger ages.

\section{Salmon biomass}

To test the density-dependent effects of intra- and interspecific competition, scale growth at each age was compared with salmon biomass estimates of mature chum, sockeye, and pink salmon within the Gulf of Alaska from Irvine and Ruggerone (2016). To estimate biomass, Irvine and Ruggerone (2016) multiplied speciesspecific mass-per-individual estimates by numerical run sizes (catch plus escapement) for chum, sockeye, and pink salmon. Using biomass rather than numerical abundance estimates to evaluate competition effects gives more influence to heavier than light salmon species (e.g., chum versus pink salmon) and also incorporates changes in size-at-age found in many salmon populations (Bigler et al. 1996; Morita and Fukuwaka 2007), which could decrease the demand for resources per individual. We used aggregate biomass estimates of mature North American chum, sockeye, and pink salmon in most of our analyses and included Asian chum salmon in one analysis.

\section{Age at maturation}

Age-at-maturity estimates for inside south coast region of $\mathrm{BC}$ (i.e., Strait of Georgia and western Vancouver Island but excluding Fraser River) chum salmon were obtained from a publicly accessible database (Ogden et al. 2015), as specific data for Big Qualicum chum salmon were not available. Big Qualicum chum salmon typically mature after 4 years at sea (Ricker 1981; Fraser et al. 1983); therefore, we calculated the proportion of south coast region $\mathrm{BC}$ chum salmon that mature after 5 years as an annual index for late-maturing individuals for each brood year.

\section{Climate conditions}

Wintertime oceanic indices have been used to explain growth and body size patterns in Pacific salmon (Agler et al. 2013; Jeffrey et al. 2017), as well as regime shifts in productivity (Helle and Hoffman 1998; Hare et al. 1999). Following standard convention (Agler et al. 2013; Litzow et al. 2014; Jeffrey et al. 2017), values of winter season variability were calculated by averaging monthly values from November to March for PDO (available from research. jisao.washington.edu/pdo/) and NPGOindices (available from www. o3d.org/npgo). December to May monthly values were averaged for the NOI index (available from http://www.pfeg.noaa.gov/ products/PFEL/modeled/indices/NOIx/noix.html); this allowed for easier comparison of results with previous studies. The propagation of El Niño Southern Oscillation takes approximately a year to affect physical processes in the North Pacific Ocean (Litzow et al. 2014), so changes in annual increment scale growth were aligned with annual (January to December) mean values of MEI from the year previous to the growth year (available from www.esrl.noaa. gov/psd/enso/mei/).

To reduce redundancy in the model and avoid overestimating precision by including highly correlated covariates (Burnham and Anderson 2002; Burnham et al. 2011), we conducted preliminary correlation and principal components analyses (PCA) of four climate indices (see online supplementary analyses ${ }^{1}$ for documentation of variable selection). PCA indicated that two components explained the most variation (75\%), and additional components were considered negligible. PDO and MEI loaded with the first PC axis and were significantly correlated with each other $(r=0.68$, $p<0.001$ ), and NPGO and NOI were weighted on the second axis and were correlated with each other $(r=0.30, p<0.001)$. We chose

${ }^{1}$ Supplementary data are available with the article through the journal Web site at http://nrcresearchpress.com/doi/suppl/10.1139/cjfas-2016-0265. 
Table 1. Number of individuals of the Big Qualicum chum salmon sampled from 1971 to 2010 across return age and sex.

\begin{tabular}{|c|c|c|c|c|c|c|}
\hline & \multicolumn{2}{|l|}{ SW3 } & \multicolumn{2}{|l|}{ SW4 } & \multicolumn{2}{|l|}{ SW5 } \\
\hline & Male & Female & Male & Female & Male & Female \\
\hline Individuals & 578 & 647 & 910 & 952 & 276 & 230 \\
\hline
\end{tabular}

Note: SW3, SW4, and SW5 refer to third, fourth, and fifth sea winters, respectively.

PDO and NPGO over the other climate indices because they directly represent physical changes in the North Pacific Ocean and are more commonly used to explain changes in growth and productivity in Pacific salmonids than the other indices.

\section{Statistical analyses}

A total of 13653 scale growth measurements were made from 3593 chum salmon collected during 1970-2010 (Table 1). The longitudinal mixed-effects model design accounted for correlations of repeated measures within an individual by treating each individual as a random effect (Singer and Willett 2009; Cheng et al. 2010; Marco-Rius et al. 2013). We found curvilinear relationships between ages and growth (Fig. 2); therefore, we used a quadratic regression model. Individual variation was accounted for by adding a random intercept term for each individual. Preliminary analyses indicated negligible differences in slopes among individuals, so we did not consider random slope terms further (as recommended by Hedeker and Gibbons (2006)). The following mixedeffects model tested hypotheses $\mathrm{H} 1, \mathrm{H} 2$, and $\mathrm{H} 3$ :
Fig. 2. Mean annual growth (mm) at each growth zone (SW) of individual Big Qualicum chum salmon that return to spawning grounds after (a) 3 years at sea (1243 individuals), (b) 4 years at sea (1887 individuals), and (c) 5 years at sea (520 individuals). Growth profiles for the maturation age are provided in panel $(d)$. On each panel $(a-d)$, bold lines represent mean fitted values for each age from quadratic regression analyses.

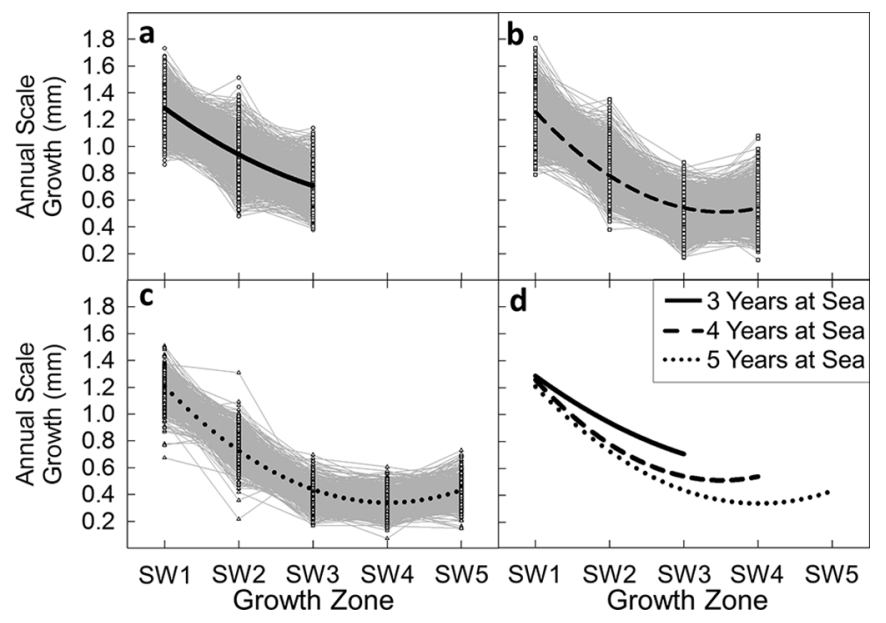

$$
\begin{aligned}
& \mathrm{SW}_{i j}=\beta_{0}+\beta_{1}\left(\mathrm{RAS}_{i j}\right)+\beta_{2}\left(A_{i j}^{2}\right)+\beta_{3}\left(A_{i j}\right)+\beta_{4}\left(\mathrm{SB}_{i j}\right)+\beta_{5}\left(\mathrm{PDO}_{i j}\right)+\beta_{6}\left(\mathrm{NPGO}_{i j}\right)+\beta_{7}\left(A_{i j} \times \mathrm{SB}_{i j}\right)+\beta_{8}\left(A_{i j} \times \mathrm{PDO}_{i j}\right) \\
& \quad+\beta_{9}\left(A_{i j} \times \mathrm{NPGO}_{i j}\right)+\beta_{10}\left(\mathrm{SB}_{i j} \times \mathrm{PDO}_{i j}\right)+\beta_{11}\left(\mathrm{SB}_{i j} \times \mathrm{NPGO}_{i j}\right)+\beta_{12}\left(\mathrm{PDO}_{i j} \times \mathrm{NPGO}_{i j}\right)+\beta_{13}\left(A_{i j} \times \mathrm{SB}_{i j} \times \mathrm{PDO}_{i j}\right) \\
& +\beta_{14}\left(A_{i j} \times \mathrm{SB}_{i j} \times \mathrm{NPGO}_{i j}\right)+\beta_{15}\left(A_{i j} \times \mathrm{PDO}_{i j} \times \mathrm{NPGO}_{i j}\right)+\beta_{16}\left(\mathrm{SB}_{i j} \times \mathrm{PDO}_{i j} \times \mathrm{NPGO}_{i j}\right)+\beta_{17}\left(A_{i j} \times \mathrm{SB}_{i j} \times \mathrm{PDO}_{i j} \times \mathrm{NPGO}_{i j}\right)+\alpha_{i}+\varepsilon_{i j}
\end{aligned}
$$

where SW is the annual scale growth between winters at sea of individual $i$ at each annuli $j$, RAS is a factor that groups three levels of return age $(3,4$, or 5$)$ with two sex levels (male or female) creating six return age - sex combinations, $A$ is the age in which SW growth occurred, SB is the summed absolute biomass of North American origin chum, pink, and sockeye salmon estimates, and $\beta_{0}-\beta_{17}$ are model parameters. We included return age, sex, salmon biomass, PDO, and NPGO as additive terms in our model (second to seventh terms of eq. 1). Because we expected interactions among age, salmon biomass, PDO, and NPGO would influence scale growth, we included multiplicative factors (eighth-seventeenth terms of eq. 1) to test for their combined effects on SW. The random intercepts for each individual $\left(a_{i}\right)$ and error term $\left(\varepsilon_{i, j}\right)$ were assumed to be independent and normally distributed, with zero mean and variance of $\sigma_{i}^{2}$ and $\sigma_{j}^{2}$, respectively.

To determine if including chum salmon from Asia had an additional effect to the abundance of North American chum salmon, we compared a model that included both Asian and North American origin chum salmon biomass with a model that only had North American origin chum salmon biomass, using conditional $R^{2}$ (Nakagawa and Schielzeth 2013). Differences between these models were insignificant (conditional $R^{2}$ was 0.86 in both cases). Consequently, Asian chum salmon biomass was not included in the full candidate model. We also considered models that did not include North American pink salmon and sockeye salmon. Most variation was explained with all three North American species, so we included them all in the full model.

We compared full and reduced models with fewer covariates using Akaike's information criteria (AIC). Reduced models (i.e., models that had fewer covariates) had greater AIC values ( $\triangle \mathrm{AIC}>45)$; therefore, we only report parameters from the full candidate model. Statistical analyses were performed using R Statistical
Language (R Core Team 2015) and the "lme4" (Bates et al. 2015), "MuMIn" (Barton 2016) packages.

To examine the effects of age, sex, salmon biomass, and climate on total scale size for each age of maturity, we predicted total scale size for male and female chum salmon that returned at SW3, SW4, and SW5 by summing fitted-value mean sea winter scale growth and $95 \%$ confidence intervals (CIs) from SW1 to SW3, SW1 to SW4, and SW1 to SW5, respectively, and under various levels of salmon biomass and climate indices. Low, medium, and high levels (i.e., 10th, 50th, and 90th percentiles, respectively) of the observed covariates were selected to represent salmon biomass and climate variables.

\section{Growth pattern implication on age of maturation}

To test the hypothesis (H4) that slow early growth delayed ageat-maturity (Morita and Fukuwaka 2007), we performed a linear regression between the annual scale growth between the first and third winters at sea (i.e., summed growth SW2 and SW3) and the proportion of chum salmon that matured at SW5 in southern BC. We used the annual scale growth between the first and third winters at sea to represent cumulative early growth because Morita and Fukuwaka (2006) found that growth during the second and third year at sea best predicted the probability of maturation for chum salmon.

\section{Results}

\section{Exploratory analyses}

Greater annual scale growth occurred at SW1 and SW2 than at growth zones SW3 or older (Fig. 2; Table 2). As well, salmon that returned to spawn at SW4 and SW5 often grew more in their final year at sea than during their penultimate year (i.e., the age ${ }^{2}$ coefficient was positive; Table 2). Of the chum salmon that returned to the Big Qualicum River, individuals that matured early (i.e., re- 
Table 2. Parameter estimates in the mixed-effects modelling of scale growth of Big Qualicum chum salmon.

\begin{tabular}{|c|c|c|c|c|}
\hline Fixed effect & Estimate & $\begin{array}{l}\text { Standard } \\
\text { error }\end{array}$ & $t$ value & $p$ value \\
\hline$\beta_{0}$, intercept & 2.1021 & 0.0133 & 158.50 & $<0.001$ \\
\hline$\beta_{1}$, return at age 3 and female & -0.0157 & 0.0047 & -3.33 & $<0.001$ \\
\hline$\beta_{1}$, return at age 4 and male & -0.1013 & 0.0042 & -23.85 & $<0.001$ \\
\hline$\beta_{1}$, return at age 4 and female & -0.1179 & 0.0042 & -27.94 & $<0.001$ \\
\hline$\beta_{1}$, return at age 5 and male & -0.2113 & 0.0055 & -38.19 & $<0.001$ \\
\hline$\beta_{1}$, return at age 5 and female & -0.2327 & 0.0058 & -39.86 & $<0.001$ \\
\hline$\beta_{1}$ age $^{2}$ & 0.0893 & 0.0009 & 103.04 & $<0.001$ \\
\hline$\beta_{3}$, age & -0.7124 & 0.0063 & -113.37 & $<0.05$ \\
\hline$\beta_{4}$, salmon biomass (SB) & -0.2795 & 0.0211 & -13.22 & $<0.001$ \\
\hline$\beta_{5}$, Pacific Decadal Oscillation Index (PDO) & -0.0003 & 0.0122 & -0.03 & 0.98 \\
\hline$\beta_{6}$, North Pacific Gyre Oscillation (NPGO) & 0.0306 & 0.0136 & 2.24 & $<0.001$ \\
\hline$\beta_{7}$, age $\times$ SB & 0.0296 & 0.0079 & 3.73 & $<0.001$ \\
\hline$\beta_{8}$, age $\times$ PDO & -0.0057 & 0.0045 & -1.27 & 0.20 \\
\hline$\beta_{9}$, age $\times$ NPGO & 0.0024 & 0.0055 & 0.44 & 0.16 \\
\hline$\beta_{10}, \mathrm{SB} \times \mathrm{PDO}$ & 0.0317 & 0.0227 & 1.40 & 0.66 \\
\hline$\beta_{11}, \mathrm{SB} \times \mathrm{NPGO}$ & -0.0277 & 0.0219 & -1.26 & 0.20 \\
\hline$\beta_{12}, \mathrm{PDO} \times \mathrm{NPGO}$ & -0.0864 & 0.0135 & -6.38 & $<0.001$ \\
\hline$\beta_{13}$, age $\times$ SB $\times$ PDO & 0.0054 & 0.0083 & 0.65 & 0.51 \\
\hline$\beta_{14}$, age $\times \mathrm{SB} \times \mathrm{NPGO}$ & -0.0070 & 0.0087 & -0.80 & 0.42 \\
\hline$\beta_{15}$, age $\times$ PDO $\times$ NPGO & 0.0216 & 0.0053 & 4.03 & $<0.001$ \\
\hline$\beta_{16}, \mathrm{SB} \times \mathrm{PDO} \times \mathrm{NPGO}$ & 0.1446 & 0.0226 & 6.40 & $<0.001$ \\
\hline$\beta_{17}$, age $\times \mathrm{SB} \times \mathrm{PDO} \times \mathrm{NPGO}$ & -0.0358 & 0.0088 & -4.08 & $<0.001$ \\
\hline Random effect & Variance & $\begin{array}{l}\text { Standard } \\
\text { deviation }\end{array}$ & & \\
\hline Intercept (individual) $\left(a_{i}\right)$ & 0.001 & 0.036 & & \\
\hline Residual $\left(e_{i j}\right)$ & 0.016 & 0.128 & & \\
\hline
\end{tabular}

turned at SW3) had greater overall scale growth rates than later maturing salmon but tended to be smaller at maturity (Fig. $2 d$; Table 2). As well, females tended to be smaller than males for each age of return (Table 2).

Temporal patterns in growth for ages of chum salmon (i.e., SW1 to SW4) were largely synchronous (Fig. 3a).We did not include SW5 growth patterns because fewer SW5 individuals were collected and only for 15 years within the data set. Although different aged chum salmon must occupy separate horizontal areas of the North Pacific Ocean (i.e., SW1 migrate up the coast, SW2 within the Gulf of Alaska, and maturing salmon return towards $\mathrm{BC}$ ), the synchronous temporal patterns suggested that factors influencing growth operate across a large spatial scale. In general, scale size at each growth zone increased from 1970 to 1975, remained relatively high until 1980, and was low until 1990. Following 1991, scale size at each growth zone increased to a peak in 2000 and subsequently decreased until 2009 and then peaked again during 2010 (Fig. 3a). Prior to 1975, the aggregate biomass of mature North American chum, sockeye, and pink salmon was approximately 300 million kilograms (Fig. 3b). Biomass increased substantially during the late 1970 s and 1980 s and subsequently remained between 500 and 700 million kilograms. The increase in aggregate biomass during the late 1970s and 1980s coincided with decreased scale size for each growth zone; however, when aggregate biomass was high during the 2000s, scale size for each growth zone increased.

Despite the observed alternating pattern of pink salmon biomass (high in odd numbered years, lower in even years; Fig. 3b), we did not observe correlative oscillations for each growth zone (Fig. 3a). This suggested that competition between Big Qualicum chum salmon and pink salmon may have been less than between Big Qualicum chum salmon and other chum salmon or sockeye salmon.

Relationships between changes in PDO and NPGO and scale growth were less detectable visually (Fig. 3c). PDO and NPGO had cyclic patterns that were not synchronous. However, during the late 1980s and 1990s, PDO was mostly positive, indicating warm ocean temperatures, and NPGO was mostly negative, indicating weak currents; this coincided with reduced scale size at each growth zone. From 1998 to 2003, scale size at each growth zone increased while NPGO was positive (i.e., stronger currents) and PDO was relatively negative (i.e., cooler ocean temperatures).

\section{Effect of competition on scale growth (H1)}

Scale growth was reduced during years of high salmon biomass, as shown by the significant negative coefficient of salmon biomass in our model $\left(\beta_{4}\right.$; Table 2$)$. Scale growth for each growth zone and total scale size were reduced across all ages and levels of climate indices when salmon biomasses were high (Figs. 4 and 5). The age $\times$ salmon biomass interaction term had a significant positive coefficient ( $\beta_{7}$; Table 2$)$, indicating that competition effects on growth were greatest for older fish.

Effect of climate on scale growth (H2)

NPGO had a significant positive effect on scale size across all growth zones of Big Qualicum chum salmon, while the effect of PDO was not significant ( $\beta_{6}$ and $\beta_{5}$, respectively; Table 2 ). As NPGO increased, scale size at each growth zone and total scale size were larger (Figs. 4 and 5). PDO may have an impact on scale growth in combination with age, NPGO, and salmon biomass, as evidenced by the significant coefficients for the interaction terms PDO $\times$ NPGO $\left(\beta_{12}\right)$, Age $\times$ PDO $\times$ NPGO $\left(\beta_{15}\right)$, and Age $\times$ SB $\times$ PDO $\times$ NPGO $\left(\beta_{17}\right)$ (see subsection below for further interpretation).

\section{Effect of climate variation and age on the density-dependent growth (H3)}

Across all conditions of climate indices and ages, increased salmon biomass was associated with reduced scale size for each growth zone, indicating that density-dependent growth is persistent regardless of climate conditions, although the intensity of 
Fig. 3. (a) Time series of standardized mean scale growth increments for Big Qualicum chum salmon for each growth zone (SW) by year of growth. (b) Estimated summed biomass of adult North America origin pink, chum, and sockeye salmon (from Irvine and Ruggerone 2016). (c) Climate indices for North Pacific Gyre Oscillation (NPGO) (solid grey line) (available from www.o3d.org/npgo) and Pacific Decadal Oscillation (PDO) (dotted black line) (available from research.jisao.washington.edu/pdo/).

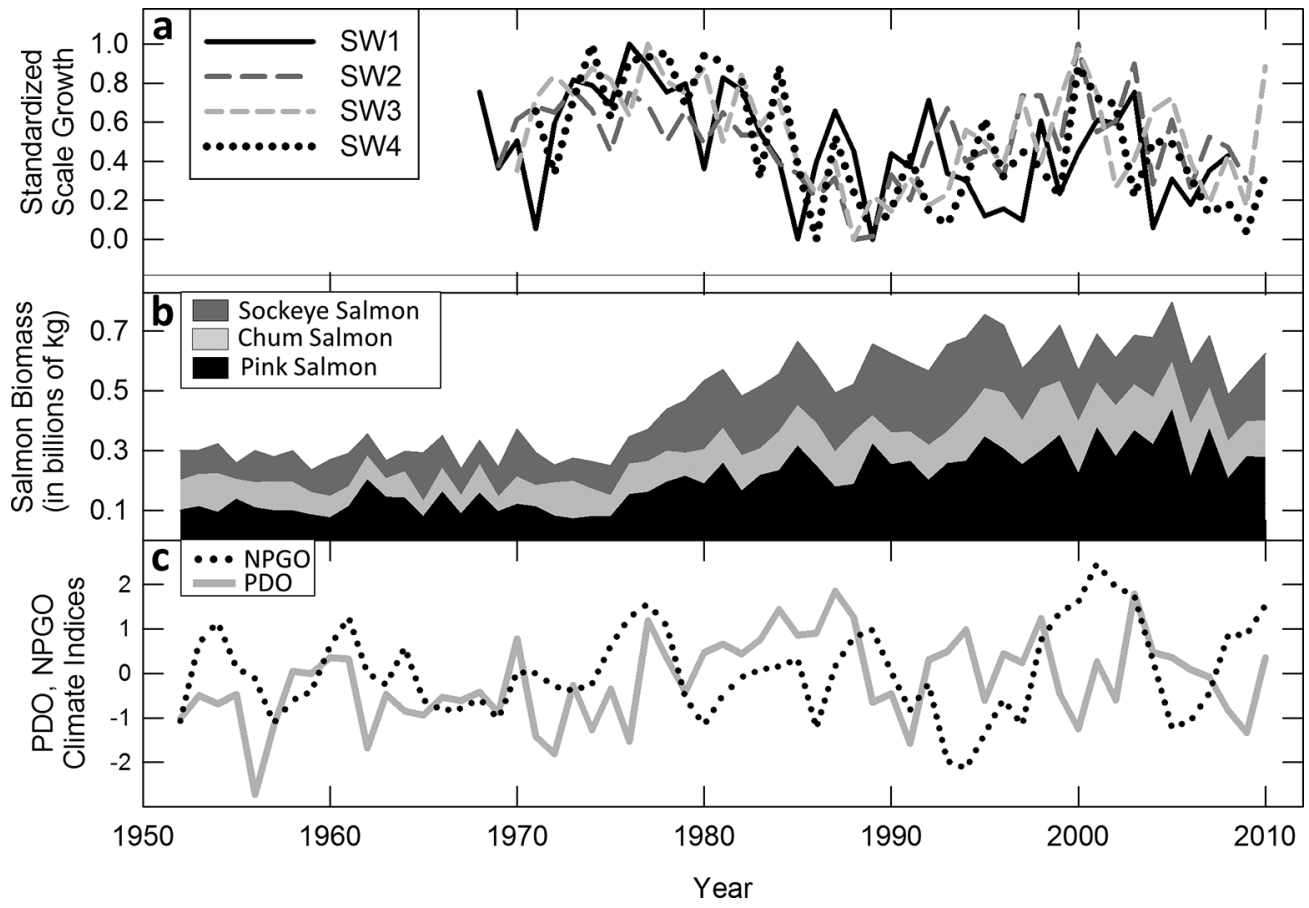

Fig. 4. Predicted annual scale growth $(\mathrm{mm})$ for each sea growth zone (SW) and level of summed North American chum, pink, and sockeye salmon biomass and (a) Pacific Decadal Oscillation (PDO) or (b) North Pacific Gyre Oscillation Index (NPGO). Low and high salmon biomass are the 10th and 90th percentiles of the observed salmon biomass, respectively. Views 1 and 2 denote separate views for each set of predictions. Medium levels of nonselected climate indices were used for each selected comparison.
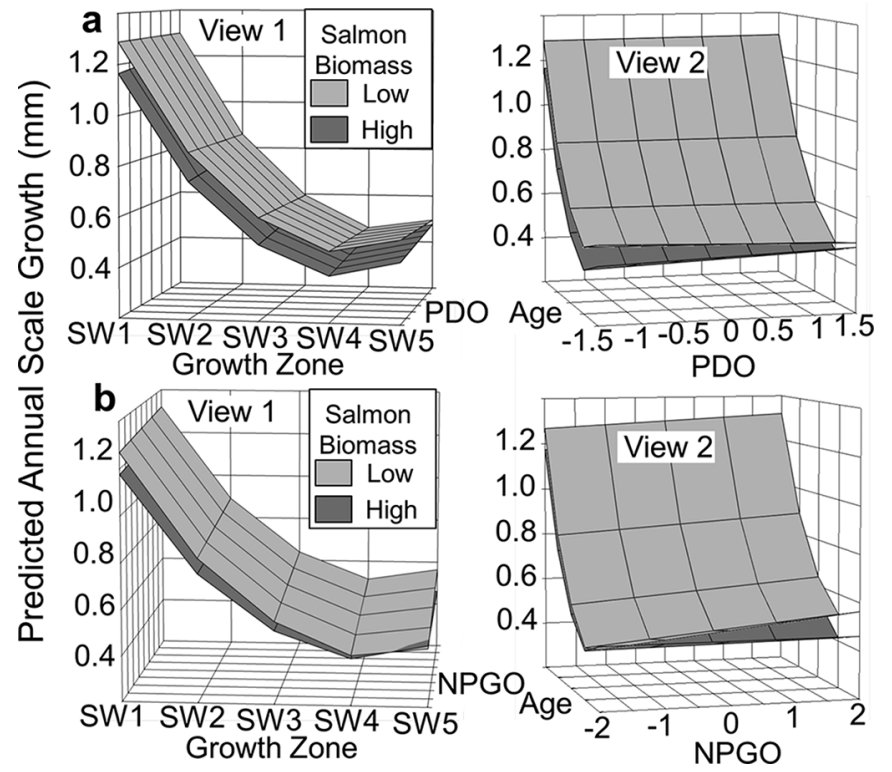

density dependence varied (Fig. 5). Interactions among age, PDO, NPGO, and salmon biomass occurred (Table 2) and confounded the associated main effects. For example, the significant interaction among salmon biomass, PDO, and NPGO suggested that when
PDO is in a cool phase (i.e., is negative) and NPGO is strong (i.e., is positive), the intensity density-dependent effects increased. This effect is illustrated by the relatively large range in predicted total scale size between low and high salmon biomass when NPGO is high and PDO is low (Fig. 5).

\section{Effect of early growth on age-at-maturity (H4)}

Older returning Big Qualicum chum salmon tended to have smaller scale size at each growth zone than younger returning fish (Fig. 2). We tested whether observed reductions in early growth within a brood was associated with a larger proportion of late-maturing individuals. On average, $21 \%, 70 \%$, and $9 \%$ of southern coast BC chum salmon returned after spending 3, 4, and 5 winters at sea, respectively. From 1970 to 1998 , the proportion of individuals that mature at after 5 years at sea increased as the early growth index decreased (Fig. 6a). Subsequently, the early growth index increased from 1990 to 1999, but then decreased after 2000; however, there was no clear trend between early growth and proportion of late-maturing individuals during that period. Early marine scale growth was inversely related to the proportion of individuals that matured late, at age 5 instead of age $4\left(R^{2}=0.15, p=0.013\right.$; Fig. $\left.6 b\right)$. Slow early marine growth was associated with later maturation.

\section{Discussion}

Variability in marine scale growth of individual Big Qualicum chum salmon was explained by density-dependent effects of competition from the summed biomass of North American chum, sockeye, and pink salmon, as well as changes in the ocean climate indices PDO and NPGO. Growth was reduced for all ages and lifehistory types (return ages) when salmon biomass was high. However, competition effects were greatest for older chum salmon, as stated in H1, consistent with the idea that older Big Qualicum chum salmon come in contact with competing salmon more than younger salmon do. As similarly reported by Jeffrey et al. (2017), 
Fig. 5. Predicted total scale size (mm; mean \pm standard error) of Big Qualicum chum salmon that return after 3, 4, or 5 years at sea for females (solid circles) and males (open circles). Panel displays predicted scale size under a regime of low (10th percentile), medium (50th percentile), or high (90th percentile) level of PDO or NPGO. Response levels (low, L; medium, M; and high, H) are also shown for summed salmon biomass for North American chum, sockeye, and pink salmon.

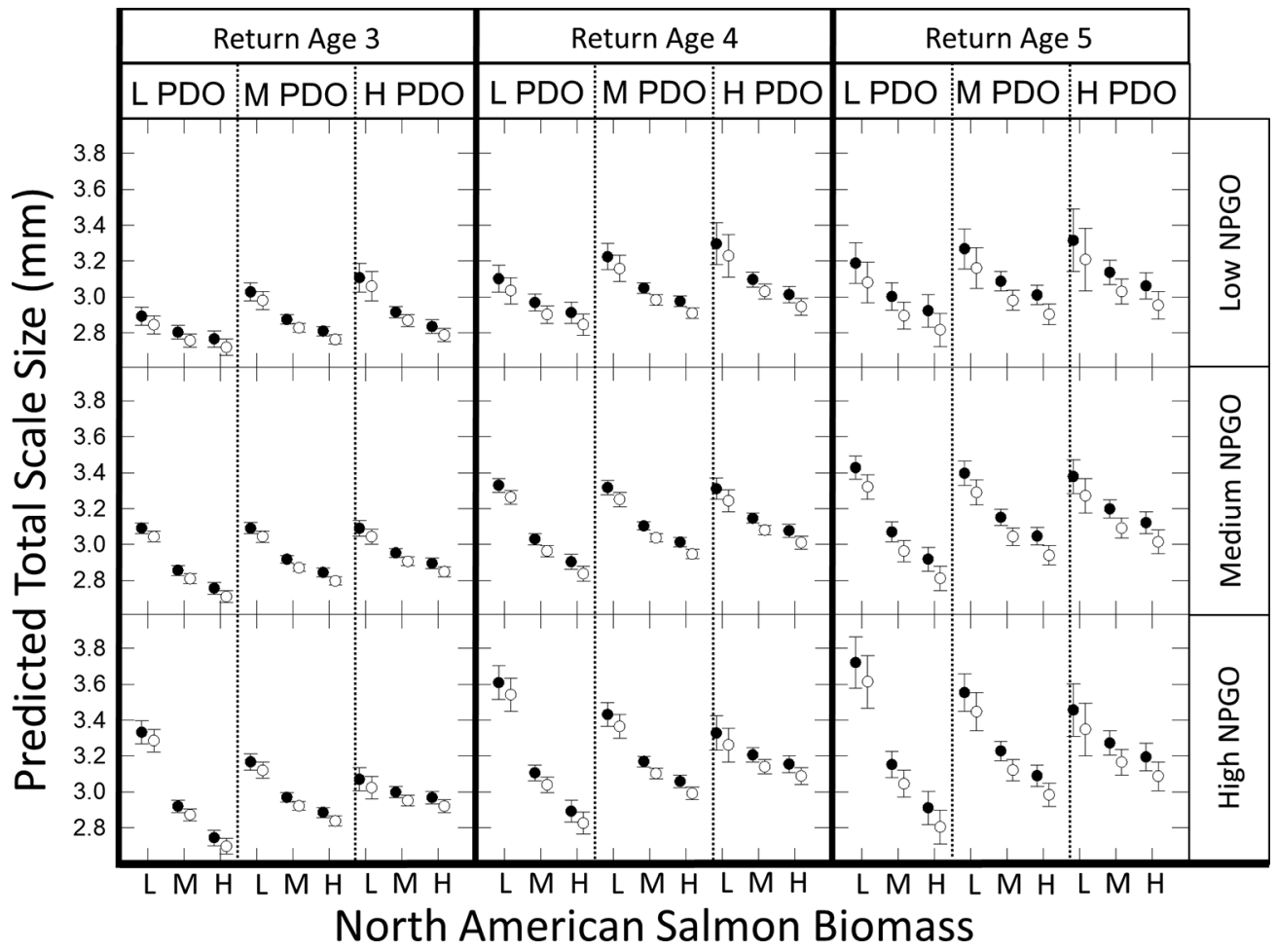

Fig. 6. (a) Time series of early growth index $(\mathrm{mm})$ from first sea winter to third year at sea for each brood of Big Qualicum chum salmon ( \pm SD, black solid line) and associated proportion of individuals that mature at SW5 (after fifth sea year) (dashed line) for interior south coast region of BC. (b) The relationship between summed scale length $(\mathrm{mm})$ from the first sea winter to the third year at sea and proportion of individuals that mature at age 5 .

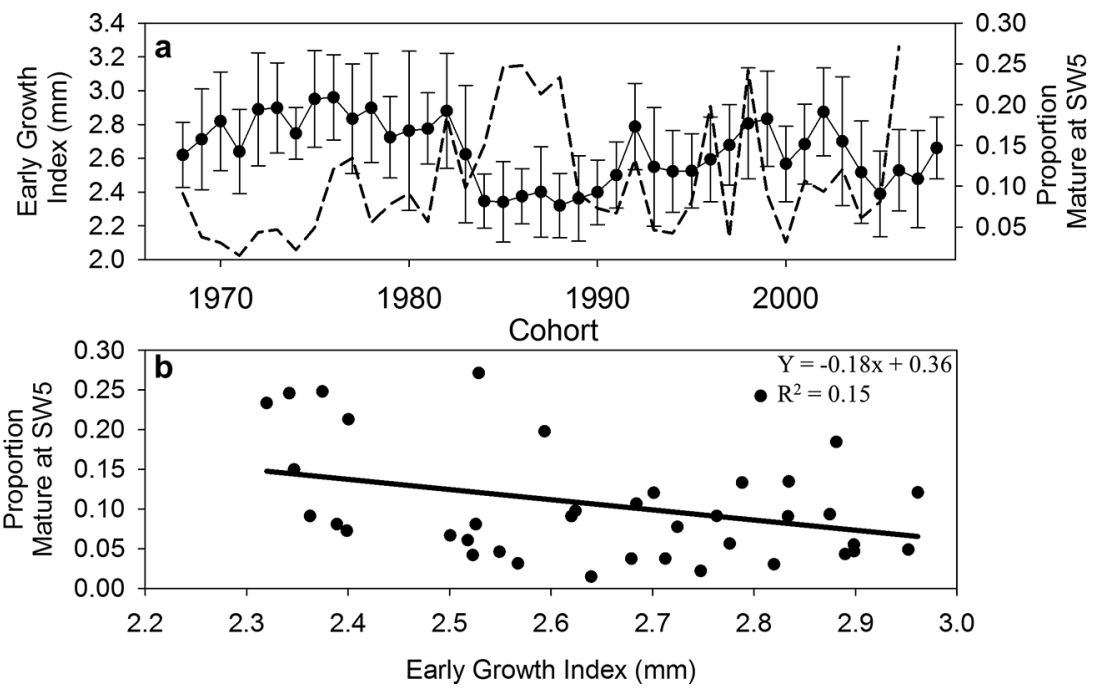

including Asian chum salmon did not explain additional variability in growth. This is not surprising given that the time series of Asian chum biomass was positively correlated with the aggregate North American biomass $\left(R^{2}=0.67, p<0.001\right)$. We cannot rule out the possibility that Asian chum salmon had an effect on the growth of Big Qualicum chum salmon given this collinearity between salmon variables.

The relative effect of competition on growth depended on climate conditions. Results from our mixed-effects model suggested that scale size increased across all growth zones during periods of high NPGO, confirming the importance of climate factors that operate at large spatial scales (H2). Depending on the sign and magnitude of climate indices, the intensity of density-dependent effects varied, supporting hypothesis H3. As NPGO became positive and PDO became negative, the intensity of density-dependent growth increased, and when the opposite occurred (NPGO negative and PDO positive), the intensity of density-dependent effects on growth was reduced. 


\section{Trends in growth, biomass, and climate variation}

Similar to what has been reported by other researchers (e.g., Seo et al. 2006; Ruggerone et al. 2012; Yasumiishi et al. 2016), we found that chum salmon exhibited density-dependent growth; as the biomass of Pacific salmon increased, scale size across growth zones and total scale size (reflecting fish size at return) decreased. Observed total scale size was higher during 1968 to 1980 than after 1980 when the biomass of competing salmon increased. Higher biomass resulted from increased hatchery production and improved survivals resulting from favourable ocean conditions (Eggers 2009; Ruggerone et al. 2010a). Reductions in average body size after 1980 were observed in Pacific salmon from both North American and Asian populations (Bigler et al. 1996; Helle and Hoffman 1998), suggesting a role of common factors such as density-dependent effects. Although we cannot say for certain which particular populations of salmon influence the growth of Big Qualicum chum salmon, our results strongly suggest that increased salmon biomass in the North Pacific Ocean resulted in smaller sizes-at-age for this population.

The choice of the index used to represent salmon abundance is important. Readily available commercial catch estimates (numbers and (or) masses) are sometimes used (e.g., Beamish et al. 2004a; Irvine and Fukuwaka 2011). However, using catch statistics can be problematic if there are major differences in exploitation among years or species. Adding numbers of fish that escape fisheries to numbers caught (e.g., Ruggerone et al. 2010b; Yasumiishi et al. 2016) is an improvement, but may inflate the potential importance of small species like pink salmon. In this study, we used biomass estimates of mature salmon that better represent the true importance of larger species than numerical estimates do. However, because salmon often recruit to fisheries in their final year, younger salmon that can have an important effect on ecosystem dynamics are ignored. Including biomass estimates of younger salmon (e.g., Jeffrey et al. 2017) can be a further improvement, particularly for long-lived species. We chose not to include younger salmon in our study, as we were unsure which populations of younger salmon were competing with Big Qualicum chum salmon. When assessing density dependence, researchers should consider the strengths and weaknesses of the various abundance indices and the methods used to derive them before deciding on which index or indices to use.

Although density-dependent effects on growth of Big Qualicum chum salmon were strong, climate variation also appeared to contribute to variability in growth and final fish size. Regardless of salmon biomass, predicted total scale size was positively associated with increases in NPGO. Changes in observed total scale size were associated with changes in NPGO, particularly when PDO was negative, reflecting cooler sea surface temperatures (Mantua and Hare 2002) that increased coastal primary productivity (Di Lorenzo et al. 2008; Kilduff et al. 2015). Metabolic costs decline when water is cooler, resulting in faster growth, especially when coupled with an increase in food availability (Farley et al. 2011; Siddon et al. 2013). In contrast, warmer sea surface temperature (i.e., positive PDO) increases metabolic costs and, coupled with lower food availability, may decrease body sizes of returning salmon (Hinch et al. 1995). During the 1980s when PDO was positive and NPGO relatively negative, chum scale growth tended to be reduced. However, it should be noted the effects of warmer oceans can be mitigated when there is lots of food; Farley and Trudel (2009) found that increased spring sea surface temperature coupled with increased prey density appeared to increase the growth of juvenile sockeye salmon in the Bering Sea.

\section{Early growth affected age of maturity}

As suggested by hypothesis $\mathrm{H} 4$, chum salmon that grew slowly during their first two marine years were more likely to delay maturation until their fifth year than salmon that grew faster during their early marine life. The correlation supporting this hypothesis was not strong, perhaps because time series of ages-atmaturity were averaged over multiple populations in southern BC. Nevertheless, this finding suggests that marine environmental conditions may have affected multiple chum salmon populations in southern BC. Consistent with our expectations, chum salmon that grew more slowly matured later and had larger total scale growth. Chum salmon exhibit a phenotypic plastic response to changes in growth-extended age at maturation during unfavorable conditions (Morita et al. 2005; Morita and Fukuwaka 2006, 2007). For example, if growth conditions are poor, such as high salmon biomass or low NPGO, then chum salmon are more likely to mature late. However, if conditions are favorable for growth, individuals are more likely to mature early, perhaps as a lifehistory strategy to reduce the likelihood of dying before spawning (Roff 1992; Stearns 1992).

\section{Reduction of growth may affect survival}

As reported for many other salmon populations (Bigler et al. 1996; Morita et al. 2005; Morita and Fukuwaka 2007), the average size-at-age of Big Qualicum chum salmon decreased the past four decades, and the proportion of older maturing individuals increased. The application of mixed-effects modelling allowed us to examine individual variation in growth rates that led us to conclude that reduced chum salmon size is likely a response to increased salmon abundance, which in recent years has been largely due to higher numbers of hatchery salmon being released (Eggers 2009; Ruggerone et al. 2010a; Irvine and Ruggerone 2016).

This study only informs us about the changes in growth of salmon that survive and return to spawn; it cannot be used to infer changes in growth of salmon that die before spawning. Nevertheless, other studies have indicated that salmon that have poor early growth are less likely to survive (Beamish et al. 2004b; Farley et al. 2011; Jonsson et al. 2011). Larger salmonids may be better able to avoid predation (Beamish and Mahnken 2001) and survive better than small salmonids when prey resources are low due to increased lipid stores (Farley et al. 2007, 2011). Larger-sized females may also be more fecund due to increased body cavity size (Beacham 1982; Beacham and Murray 1987; Dickerson et al. 2002), gain better oviposition territories (Fleming and Gross 1994), and dig deeper egg pockets to protect embryos from scour (Steen and Quinn 1999). Declining abundances for some wild salmon populations may be a consequence of increased mortality due to reductions in size-at-age.

Although beyond the scope of this study, decreases to body size in harvested fish species have also been the result of intensive and selective fishing in natural and experimental populations (Hard et al. 2008; Diaz-Pauli and Heino 2014). Fisheries that select older or larger size classes can cause directional selection away from older or larger maturation of age because these fish experience greater mortality (Trippel 1995; Law 2000; Marshall and Browman 2007). Fukuwaka and Morita (2008) found evidence that following the closure of the Japanese high seas gillnet fishery, the age of maturation in Asian chum salmon increased. Efforts to reduce harvest on coho, pink, and sockeye salmon in North America (Irvine and Akenhead 2013; Irvine et al. 2014) may have also resulted in increased body size within some commercial catches (Jeffrey et al. 2017). However, because the age of maturation for many Pacific salmon populations has increased and even surpassed historical levels, it is less likely that fisheries-induced evolution has caused directional selection for smaller-sized individuals within these populations (Morita et al. 2005).

Large variations in salmon biomass and climate explained changes in growth of chum salmon in southern BC. To the best of our knowledge, ours is the first study to use a longitudinal model design with repeated measures of growth of individual fish to examine whether and how interactions between density dependence and climate affect salmon growth. This approach could be 
applied to examine factors that affect other salmon populations and species. In addition, following Jeffrey et al. (2017), we suggest that future studies should consider the role of fishing on salmon growth, and researchers should be aware of the strengths and weaknesses of the various abundance indices. We expect that salmon populations may continue to show reduced sizes-at-age and increased ages at maturation if salmon abundance remains high due to favorable conditions and enhancement (Ruggerone et al. 2010b) and ocean climate continues to vary due to anthropogenic warming (Di Lorenzo et al. 2010; Cai et al. 2014). Reduced early marine growth and extended marine residence are expected to increase natural mortality. Because hatcheries continue to play a major role in producing salmon in the North Pacific Ocean (Eggers 2009; Ruggerone et al. 2010b; Irvine and Ruggerone 2016), international government agencies and stakeholder groups need to better understand the implications of hatchery releases on the growth and survival of wild stocks of Pacific salmon (Holt et al. 2008).

\section{Acknowledgements}

We appreciate the assistance of the many biologists and technicians who worked at Big Qualicum River Hatchery over the years. We acknowledge the contribution of members of the DFO Sclerochronology Lab: Shayne MacLellan for her support and Judy MacArthur and Mary Jane Hudson for remeasuring scales for quality control and assisting with some of the yearly scale measurements. We also recognize the assistance of Barbara Dunsmore, who provided biological data for Big Qualicum chum salmon, and Nora Crosby, who retrieved scales from the DFO archives. We thank Carl Schwarz for advice on statistical analyses, as well as Greg Ruggerone for his consultation on preliminary results. The first author thanks his Ph.D. supervisor, Tom Nudds, for the leave of absence to pursue this study and DFO's International Governance Strategy for financial support. We thank two anonymous reviewers for their constructive criticism of the manuscript.

\section{References}

Agler, B.A., Ruggerone, G.T., Wilson, L.I., and Mueter, F.J. 2013. Historical growth of Bristol Bay and Yukon River, Alaska chum salmon (Oncorhynchus keta) in relation to climate and inter- and intraspecific competition. Deep. Res. Part II Top. Stud. Oceanogr. 94: 165-177. doi:10.1016/j.dsr2.2013.03.028.

Azumaya, T., and Ishida, Y. 2000. Density interactions between pink salmon (Oncorhynchus gorbuscha) and chum salmon (O. keta) and their possible effects on distribution and growth in the North Pacific Ocean and Bering Sea [online]. N. Pac. Anadr. Fish Comm. Bull. 2: 165-174. Available from http:/l www.npafc.org.

Barton, K. 2016. MuMin: Multi-Model Inference [online]. R Package, version 1.15.6. Available from https://cran.r-project.org/package=MuMIn.

Bates, D., Mächler, M., Bolker, B., and Walker, S. 2015. Fitting linear mixedeffects models using lme4. J. Stat. Softw. 67: 1-48. doi:10.18637/jss.v067.i01.

Beacham, T.D. 1982. Fecundity of coho salmon (Oncorhynchus kisutch) and chum salmon (O. keta) in the northeast Pacific Ocean. Can. J. Zool. 60(6): 1463-1469. doi:10.1139/z82-195.

Beacham, T.D., and Murray, C.B. 1987. Adaptive variation in body size, age, morphology, egg size, and developmental biology of chum salmon (Oncorhynchus keta) in British Columbia. Can. J. Fish. Aquat. Sci. 44(2): 244-261. doi:10.1139/f87-034.

Beamish, R., and Mahnken, C. 2001. A critical size and period hypothesis to explain natural regulation of salmon abundance and the linkage to climate and climate change. Prog. Oceanogr. 49: 423-437. doi:10.1016/S0079-6611(01) 00034-9.

Beamish, R.J., Benson, A.J., Sweeting, R.M., and Neville, C.M. 2004a. Regimes and the history of the major fisheries off Canada's west coast. Prog. Oceanogr. 60: 355-385. doi:10.1016/j.pocean.2004.02.009.

Beamish, R.J., Mahnken, C., and Neville, C.M. 2004b. Evidence that reduced early marine growth is associated with lower marine survival of coho salmon. Trans. Am. Fish. Soc. 133: 26-33. doi:10.1577/T03-028.

Beauchamp, D.A. 2009. Bioenergetic ontogeny: linking climate and massspecific feeding to life-cycle growth and survival of salmon. In Pacific Salmon: Ecology and Management of Western Alaska's Populations. American Fisheries Society Symposium 70. Edited by C. Zimmerman and C.C. Krueger. American Fisheries Society, Bethesda, Maryland. pp. 53-72.

Behrenfeld, M.J., O’Malley, R.T., Siegel, D.A., McClain, C.R., Sarmiento, J.L., Feldman, G.C., Milligan, A.J., Falkowski, P.G., Letelier, R.M., and Boss, E.S. 2006. Climate-driven trends in contemporary ocean productivity. Nature, 444: 752-755. doi:10.1038/nature05317. PMID:17151666.
Bigler, B.S., Welch, D.W., and Helle, J.H. 1996. A review of size trends among North Pacific salmon (Oncorhynchus spp.). Can. J. Fish. Aquat. Sci. 53(1): 455465. doi:10.1139/f95-181.

Burnham, K.P., and Anderson, D.R. 2002. Model selection and multimodel inference: a practical information theoretic approach. 2nd ed. SpringerVerlag, New York.

Burnham, K.P., Anderson, D.R., and Huyvaert, K.P. 2011. AIC model selection and multimodel inference in behavioral ecology: some background, observations, and comparisons. Behav. Ecol. Sociobiol. 65: 23-35. doi:10.1007/s00265010-1029-6.

Cai, W., Borlace, S., Lengaigne, M., van Rensch, P., Collins, M., Vecchi, G., Timmermann, A., Santoso, A., McPhaden, M.J., Wu, L., England, M.H., Wang, G., Guilyardi, E., and Jin, F.-F. 2014. Increasing frequency of extreme El Niño events due to greenhouse warming. Nat. Clim. Change, 4: 111-116. doi:10.1038/nclimate2100.

Cheng, J., Edwards, L.J., Maldonado-Molina, M.M., Komro, K.A., and Muller, K.E. 2010. Real longitudinal data analysis for real people: building a good enough mixed model. Stat. Med. 29: 504-520. doi:10.1002/sim.3775. PMID:20013937.

Davis, N.D., Fukuwaka, M., Armstrong, J.L., and Myers, K.W. 2004. Salmon food habits studies in the Bering Sea, 1960 to present [online]. NPAFC Technical Rep. 6: 24-28. Available from http://www.npafc.org/new/publications.html.

Di Lorenzo, E., Schneider, N., Cobb, K.M., Franks, P.J.S., Chhak, K., Miller, A.J., McWilliams, J.C., Bograd, S.J., Arango, H., Curchitser, E., Powell, T.M., and Rivière, P. 2008. North Pacific Gyre Oscillation links ocean climate and ecosystem change. Geophys. Res. Lett. 35: 1-6. doi:10.1029/2007GL032838.

Di Lorenzo, E., Cobb, K.M., Furtado, J.C., Schneider, N., Anderson, B.T., Bracco, A., Alexander, M.A., and Vimont, D.J. 2010. Central Pacific El Niño and decadal climate change in the North Pacific Ocean. Nat. Geosci. 3: 762-765. doi:10.1038/ngeo984.

Diaz-Pauli, B., and Heino, M. 2014. What can selection experiments teach us about fisheries-induced evolution? Biol. J. Linn. Soc. 111: 485-503. doi:10.1111/ bij.12241.

Dickerson, B.R., Quinn, T.P., and Willson, M.F. 2002. Body size, arrival date, and reproductive success of pink salmon, Oncorhynchus gorbuscha. Ethol. Ecol. Evol. 14: 29-44. doi:10.1080/08927014.2002.9522759.

Eggers, D.M. 2009. Historical biomass of pink, chum, and sockeye salmon in the North Pacific Ocean. Am. Fish. Soc. Symp. 70: 1-40.

Farley, E.V., and Trudel, M. 2009. Growth rate potential of juvenile sockeye salmon in warmer and cooler years on the eastern Bering Sea shelf. J. Mar. Biol. 2009: 1-10. doi:10.1155/2009/640215.

Farley, E.V.J., Murphy, J.M., Adkison, M.D., Eisner, L.B., Helle, J.H., Moss, J.H., and Nielsen, J. 2007. Early marine growth in relation to marine-stage survival rates for Alaska sockeye salmon (Oncorhychus nerka). Fish. Bull. 105: 121-139. Available from http://fishbull.noaa.gov/1051/farley.pdf.

Farley, E.V., Starovoytov, A., Naydenko, S., Heintz, R., Trudel, M., Guthrie, C., Eisner, L., and Guyon, J.R. 2011. Implications of a warming eastern Bering Sea for Bristol Bay sockeye salmon. ICES J. Mar. Sci. 68: 1138-1146. doi:10.1093/ icesjms/fsr021.

Fleming, I.A., and Gross, M.R. 1994. Breeding competition in a Pacific salmon (coho: Oncorhynchus kisutch): measures of natural and sexual selection. Evolution, 48: 637-657. doi:10.2307/2410475.

Fraser, F.J., Perry, E.A., and Lightly, D.T. 1983. Big Qualicum River salmon development project. Vol. 1: A biological assessment, 1959-1972. Canadian Technical Report of Fisheries and Aquatic Sciences No. 1189.

Fukuwaka, M., and Morita, K. 2008. Increase in maturation size after the closure of a high seas gillnet fishery on hatchery-reared chum salmon Oncorhynchus keta. Evol. Appl. 1: 376-387. doi:10.1111/j.1752-4571.2008.00029.x. PMID:25567638.

Hard, J.J., Gross, M.R., Heino, M., Hilborn, R., Kope, R.G., Law, R., and Reynolds, J.D. 2008. Evolutionary consequences of fishing and their implications for salmon. Evol. Appl. 1: 388-408. doi:10.1111/j.1752-4571.2008.00020.x. PMID:25567639.

Hare, S.R., and Mantua, N.J. 2000. Empirical evidence for North Pacific regime shifts in 1977 and 1989. Prog. Oceanogr. 47: 103-145. doi:10.1016/S0079-6611(00) 00033-1.

Hare, S.R., Mantua, N.J., and Francis, R.C. 1999. Inverse production regimes: Alaska and west coast Pacific salmon. Fisheries, 24: 6-14. doi:10.1577/15488446(1999)024<0006:IPR>2.0.CO;2.

Hartt, A.C., and Dell, M.B. 1986. Early oceanic migration and growth of juvenile Pacific salmon and steelhead trout [online]. Int. N. Pac. Fish. Comm. Bull. 46. Available from http://www.npafc.org.

Hedeker, D., and Gibbons, R. 2006. Longitudinal data analysis. WileyInterscience, Hoboken, N.J.

Helle, J.H., and Hoffman, M.S. 1998. Changes in size and age at maturity of two North American stocks of chum salmon (Oncorhynchus keta) before and after a major regime shift in the North Pacific Ocean [online]. N. Pac. Anadr. Fish Comm. Bull. 1: 81-89. Available from http://www.npafc.org.

Hinch, S.G., Healey, M.C., Diewert, R.E., Henderson, M.A., Thomson, K.A., Hourston, R., and Juanes, F. 1995. Potential effects of climate change on marine growth and survival of Fraser River sockeye salmon. Can. J. Fish. Aquat. Sci. 52(12): 2651-2659. doi:10.1139/f95-854.

Hogan, F., and Friedland, K.D. 2010. Retrospective growth analysis of Atlantic salmon Salmo salar and implications for abundance trends. J. Fish Biol. 76: 2502-2520. doi:10.1111/j.1095-8649.2010.02650.x. PMID:20557605. 
Holt, C.A., Rutherford, M.B., and Peterman, R.M. 2008. International cooperation among nation-states of the North Pacific Ocean on the problem of competition among salmon for a common pool of prey resources. Mar. Pol. 32: 607-617. doi:10.1016/j.marpol.2007.11.001.

Irvine, J.R., and Akenhead, S.A. 2013. Understanding smolt survival trends in sockeye salmon. Mar. Coast. Fish. 5: 303-328. doi:10.1080/19425120.2013. 831002.

Irvine, J.R., and Fukuwaka, M.-A. 2011. Pacific salmon abundance trends and climate change. ICES J. Mar. Sci. 68: 1122-1130. doi:10.1093/icesjms/fsq199.

Irvine, J.R., and Ruggerone, G.T. 2016. Provisional estimates of numbers and biomass for natural-origin and hatchery-origin pink, chum, and sockeye salmon in the North Pacific, 1952-2015. NPAFC Doc. 1660. Fisheries and Oceans Canada, Pacific Biological Station and Natural Resources Consultants, Inc. doi:10.13140/RG.2.1.5179.0960.

Irvine, J.R., Michielsens, C.J.G., O’Brien, M., White, B.A., and Folkes, M. 2014. Increasing dominance of odd-year returning pink salmon [online]. Trans. Am. Fish. Soc. 143: 939-956. Available from http://www.tandfonline.com/doi/ abs/10.1080/00028487.2014.889747.

Jeffrey, K.M., Côté, I.M., Irvine, J.R., and Reynolds, J.D. 2017. Changes in body size of Canadian Pacific salmon over six decades. Can. J. Fish. Aquat. Sci. 74(2). 191-201. doi:10.1139/cjfas-2015-0600.

Jonsson, B., Duffy, E.J., and Beauchamp, D.A. 2011. Rapid growth in the early marine period improves the marine survival of Chinook salmon (Oncorhynchus tshawytscha) in Puget Sound, Washington. Can. J. Fish. Aquat. Sci. 68(2): 232-240. doi:10. 1139/F10-144.

Kaeriyama, M., Nakamura, M., Edpalina, R., Bower, J.R., Yamaguchi, H., Walker, R.V., and Myers, K.W. 2004. Change in feeding ecology and trophic dynamics of Pacific salmon (Oncorhynchus spp.) in the central Gulf of Alaska in relation to climate events. Fish. Oceanogr. 13: 197-207. doi:10.1111/j.1365-2419. 2004.00286.x.

Kilduff, D.P., Di Lorenzo, E., Botsford, L.W., and Teo, S.L.H. 2015. Changing central Pacific El Niños reduce stability of North American salmon survival rates. Proc. Natl. Acad. Sci. U.S.A. 112: 10962-10966. doi:10.1073/pnas.1503190112. PMID:26240365.

Kozłowski, J. 1992. Optimal allocation of resources to growth and reproduction: implications for age and size at maturity. Trends Ecol. Evol. 7: 15-19. doi:10. 1016/0169-5347(92)90192-E. PMID:21235937.

Law, R. 2000. Fishing, selection, and phenotypic evolution. ICES J. Mar. Sci. 57: 659-668. doi:10.1006/jmsc.2000.0731.

Levin, P.S., Zabel, R.W., and Williams, J.G. 2001. The road to extinction is paved with good intentions: negative association of fish hatcheries with threatened salmon. Proc. R. Soc. B Biol. Sci. 268: 1153-1158. doi:10.1098/rspb.2001.1634.

Litzow, M.A., Mueter, F.J., and Hobday, A.J. 2014. Reassessing regime shifts in the North Pacific: incremental climate change and commercial fishing are necessary for explaining decadal-scale biological variability. Glob. Chang. Biol. 20: 38-50. doi:10.1111/gcb.12373. PMID:23996901.

Mantua, N.J., and Hare, S.R. 2002. The Pacific Decadal Oscillation. J. Oceanogr. 58: 35-44. doi:10.1023/A:1015820616384.

Mantua, N.J., Hare, S.R., Zhang, Y., Wallace, J.M., and Francis, R.C. 1997. A Pacific interdecadal climate oscillation with impacts on salmon production. Bull. Am. Meteorol. Soc. 78: 1069-1079. doi:10.1175/1520-0477(1997)078<1069: APICOW $>2.0 . C O ; 2$.

Marco-Rius, F., Caballero, P., Morán, P., and Garcia de Leaniz, C. 2013. Mixedeffects modelling of scale growth profiles predicts the occurrence of early and late fish migrants. PLoS ONE, 8: e61744. doi:10.1371/journal.pone.0061744. PMID:23613922.

Marr, J.C. 1943. Age, length and weight studies of three species of Columbia River salmon (Oncorhynchus keta, O. gorbuscha and O. kisutch). Stanford Ichthyol. Bull. 2: 157-197. [Natural History Museum of Stanford University.]

Marshall, C.T., and Browman, H.I. 2007. Disentangling the causes of maturation trends in exploited fish populations. Mar. Ecol. Prog. Ser. 335: 249-251. doi: 10.3354/meps335249.

Martinson, E.C., Helle, J.H., Scarnecchia, D.L., and Stokes, H.H. 2008. Densitydependent growth of Alaska sockeye salmon in relation to climate-oceanic regimes, population abundance, and body size, 1925 to 1998. Mar. Ecol. Prog. Ser. 370: 1-18. doi:10.3354/meps07665.

McCarthy, J.L., Friedland, K.D., and Hansen, L.P. 2008. Monthly indices of the post-smolt growth of Atlantic salmon from the Drammen River, Norway. J. Fish Biol. 72: 1572-1588. doi:10.1111/j.1095-8649.2008.01820.x.

McPhee, M.V., Leon, J.M., Wilson, L.I., Siegel, J.E., and Agler, B.A. 2016. Changing growth and maturity in western Alaskan Chinook salmon, Oncoryhnchus tshawytscha, Brood Years 1975-2005. N. Pac. Anadr. Fish Comm. Bull. 6. 307327. doi:10.23849/npafcb6/307.327.

Morita, K., and Fukuwaka, M. 2006. Does size matter most? The effect of growth history on probabilistic reaction norm for salmon maturation. Evolution, 60: 1516-1521. doi:10.1111/j.0014-3820.2006.tb01230.x. PMID:16929668.

Morita, K., and Fukuwaka, M. 2007. Why age and size at maturity have changed in Pacific salmon. Mar. Ecol. Prog. Ser. 335: 289-294. doi:10.3354/meps335289.

Morita, K., Morita, S.H., Fukuwaka, M., and Matsuda, H. 2005. Rule of age and size at maturity of chum salmon (Oncorhynchus keta): implications of recent trends among Oncorhynchus spp. Can. J. Fish. Aquat. Sci. 62(12): 2752-2759. doi:10.1139/f05-182.

Myers, K.W., Aydin, K.Y., Walker, R.V., Fowler, S., and Dahlberg, M.L. 1996. Known ocean ranges of stocks of Pacific salmon and steelhead as shown by tagging experiments, 1956-1995 [online]. NPAFC Doc. 192. Seattle, Wash. Available from http://www.npafc.org.

Myers, K.W., Klovach, N.V., Gritsenko, O.F., Urawa, S., and Royer, T.C. 2007. Stock-specific distributions of Asian and North American salmon in the open ocean, interannual changes, and oceanographic conditions [online]. N. Pac. Anadr. Fish Comm. Bull. 4: 159-177. Available from http://www.npafc.org.

Nakagawa, S., and Schielzeth, H. 2013. A general and simple method for obtaining $R^{2}$ from generalized linear mixed-effects models. Methods Ecol. Evol. 4: 133-142. doi:10.1111/j.2041-210x.2012.00261.x

Ogden, A.D., Irvine, J.R., English, K.K., Grant, S., Hyatt, K.D., Godbout, L., and Holt, C.A. 2015. Productivity (rescruits-per-spawner) data for sockeye, pink and chum salmon from British Columbia. Can. Tech. Rep. Fish. Aquat. Sci. 3130.

Oka, G., Irvine, J.R., Holt, C., Tucker, S., Gillespie, D., and Fitzpatrick, L. 2012. Temporal growth patterns of Big Qualicum River chum salmon (Oncorhynchus keta) in the North Pacific Ocean [online]. NPAFC Doc. 1429. Available from http://www.npafc.org.

Pyper, B.J., and Peterman, R.M. 1999. Relationship among adult body length, abundance, and ocean temperature for British Columbia and Alaska sockeye salmon (Oncorhynchus nerka), 1967-1997. Can. J. Fish. Aquat. Sci. 56(10): 17161720. doi:10.1139/f99-167.

R Core Team. 2015. R: a language and environment for statistical computing [online]. Vienna, Austria. Available from https://www.r-project.org/.

Ricker, W.E. 1973. Linear regressions in fishery research. J. Fish. Res. Board Can. 30(3): 409-434. doi:10.1139/f73-072.

Ricker, W.E. 1976. Review of the rate of growth and mortality of pacific salmon in salt water, and noncatch mortality caused by fishing. J. Fish. Res. Board Can. 33(7): 1483-1524. doi:10.1139/f76-191.

Ricker, W.E. 1981. Changes in the average size and average age of Pacific salmon. Can. J. Fish. Aquat. Sci. 38(12): 1636-1656. doi:10.1139/f81-213.

Roff, D.A. 1992. The evolution of life histories: theory and analysis. Chapman and Hall, New York.

Ruggerone, G.T., Peterman, R.M., Dorner, B., and Myers, K.W. 2010a. Magnitude and trends in abundance of hatchery and wild pink salmon, chum salmon, and sockeye salmon in the North Pacific Ocean. Mar. Coast. Fish. 2: 306-328. doi:10.1577/C09-054.1.

Ruggerone, G.T., Peterman, R.M., Dorner, B., Myers, K.W., and Mantua, N.J. $2010 \mathrm{~b}$. Abundance of adult hatchery and wild salmon by region of the North Pacific. Sch. Aquat. Fish. Sci. Univ. Wash. 1001.

Ruggerone, G.T., Agler, B.A., and Nielsen, J.L. 2012. Evidence for competition at sea between Norton Sound chum salmon and Asian hatchery chum salmon. Environ. Biol. Fishes, 94: 149-163. doi:10.1007/s10641-011-9856-5.

Schwing, F.B., Murphree, T., and Green, P.M. 2002. The Northern Oscillation Index (NOI): a new climate index for the northeast Pacific. Prog. Oceanogr. 53: 115-139, doi:10.1016/S0079-6611(02)00027-7.

Sebens, K.P. 1987. The ecology of indeterminate growth in animals. Annu. Rev. Ecol. Syst. 18: 371-407. doi:10.1146/annurev.es.18.110187.002103.

Seeb, L.W., Crane, P.A., Kondzela, C.M., Wilmot, R.L., Urawa, S., Varnavskaya, N.V., and Seeb, J.E. 2004. Migration of Pacific rim chum salmon on the high seas: insights from genetic data. Environ. Biol. Fishes, 69: 21-36. doi:10.1023/B: EBFI.0000022900.82523.63.

Seo, H., Kim, S., Seong, K., and Kang, S. 2006. Variability in scale growth rates of chum salmon (Oncorhynchus keta) in relation to climate changes in the late 1980s. Prog. Oceanogr. 68: 205-216. doi:10.1016/j.pocean.2006.02.003.

Siddon, E.C., Kristiansen, T., Mueter, F.J., Holsman, K.K., Heintz, R.A., and Farley, E.V. 2013. Spatial match-mismatch between juvenile fish and prey provides a mechanism for recruitment variability across contrasting climate conditions in the eastern Bering Sea. PLoS ONE, 8: e84526. doi:10.1371/journal.pone. 0084526. PMID:24391963.

Singer, J.D., and Willett, J.B. 2009. Applied longitudinal data analysis modeling change and event occurrence. Oxford University Press, New York.

Stearns, S.C. 1992. The evolution of life histories. Oxford University Press, New York.

Steen, R.P., and Quinn, T.P. 1999. Egg burial depth by sockeye salmon (Oncorhynchus nerka): implications for survival of embryos and natural selection on female body size. Can. J. Zool. 77(5): 836-841. doi:10.1139/z99-020.

Tadokoro, K., Ishida, Y., Davis, N.D., Ueyanagi, S., and Sugimoto, T. 1996. Change in chum salmon (Oncorhynchus keta) stomach contents associated with fluctuation of pink salmon (0. gorbuscha) abundance in the central subarctic Pacific and Bering Sea. Fish. Oceanogr. 5: 89-99. doi:10.1111/j.1365-2419. 1996.tb00108.x.

Trippel, E.A. 1995. Age at maturity as a stress indicator in fisheries. Bioscience, 45: 759-771. doi:10.2307/1312628.

Urawa, S., Sato, S., Crane, P.A., and Agler, B. 2009. Stock-specific ocean distribution and migration of chum salmon in the Bering Sea and North Pacific Ocean [online]. N. Pac. Anadr. Fish Comm. Bull. 5: 131-146. Available from http://www.npafc.org.

Welch, D.W., and Parsons, T.R. 1993. $\delta 13 \mathrm{C}-\delta 15 \mathrm{~N}$ values as indicators of trophic 
position and competitive overlap for Pacific salmon (Oncorhynchus spp.). Fish. Oceanogr. 2: 11-23. doi:10.1111/j.1365-2419.1993.tb00008.x.

Wells, B.K., Grimes, C.B., Field, J.C., and Reiss, C.S. 2006. Covariation between the average lengths of mature coho (Oncorhynchus kisutch) and Chinook salmon (O. tshawytscha) and the ocean environment. Fish. Oceanogr. 15: 6779. doi:10.1111/j.1365-2419.2005.00361.x.

Wolter, K., and Timlin, M.S. 2011. El Niño/Southern Oscillation behaviour since
1871 as diagnosed in an extended multivariate ENSO index (MEI.ext). Int. J. Climatol. 31: 1074-1087. doi:10.1002/joc.2336.

Yasumiishi, E.M., Criddle, K.R., Helle, J.H., Hillgruber, N., and Mueter, F. 2016. Effect of population abundance and climate on the growth of 2 populations of chum salmon (Oncorhynchus keta) in the eastern north pacific ocean. Fish. Bull. 114: 203-219. doi:10.7755/FB.114.2.7. 